\title{
Undernutrition in Adults Hospitalized Patients: Magnitude and Associated Factors at the University Hospital of Bobo-Dioulasso
}

\author{
Léon G. Blaise Savadogo1,2 ${ }^{\circ}$, Seydou Traoré2, Clément Z. Meda',2, Joseph Bamouni2 \\ ${ }^{1}$ Department of Epidemiology and Public Health, Child and Mother Health, Nutrition and Survival Unit, Institut Supérieur des \\ Sciences de la Santé, Bobo Dioulasso, Burkina Faso \\ ${ }^{2}$ CHUSS (University Hospital of Bobo Dioulasso), Bobo-Dioulasso, Burkina Faso \\ Email: gueswende@hotmail.com
}

How to cite this paper: Savadogo, L.G.B., Traoré, S., Meda, C.Z. and Bamouni, J. (2019) Undernutrition in Adults Hospitalized Patients: Magnitude and Associated Factors at the University Hospital of Bobo-Dioulasso. Open Journal of Epidemiology, $9,27-35$

https://doi.org/10.4236/ojepi.2019.91003

Received: December 1, 2018

Accepted: January 5, 2019

Published: January 8, 2019

Copyright $\odot 2019$ by authors and Scientific Research Publishing Inc. This work is licensed under the Creative Commons Attribution International License (CC BY 4.0).

http://creativecommons.org/licenses/by/4.0/

(c) (i) Open Access

\begin{abstract}
Background: Despite numerous advances in medicine and clinical care, in developing countries, adult undernutrition is overlooked and not considered as a sufficient medical priority. The objective of this study was to identify the magnitude of adult undernutrition and its associated factors in hospitalized patients. Methods: Cross-sectional study, performed in the university hospital in Bobo-Dioulasso, from August to September 2016, in a sample of 244 adult individuals. Patients were included in the study consecutively to their admission. A structured questionnaire was applied consisting of anthropometric, clinical and dietary data. The patients were evaluated and dichotomized into undernourished and non-undernourished. The rate of undernutrtion was reported using and associated factors were tested using the unadjusted crude Odds ratios (COR) with 95\% confidence interval (95\% CI) and the Chi-square test. Results: Undernutrition occurred in $32.4 \%$ of the sample and at the univariate analysis, the variables associated with undernutrition were: recent and involuntary weight loss $(\mathrm{COR}=2.58,95 \% \mathrm{CI}=1.45-4.59, \mathrm{p}$ $<0.001)$; disease chronic evolution $(\mathrm{COR}=2.29,95 \% \mathrm{CI}=1.23-4.23, \mathrm{p}=$ $0.008)$ and females $(\mathrm{COR}=1.76,95 \% \mathrm{CI}=1.02-6.06, \mathrm{p}=0.04)$. Conclusion: Adult undernutrition is common in hospitalized patients. A proper early diagnosis and therapy need to be considered as medical priority of the entire healthcare team that treats adult's inpatients.
\end{abstract}

\section{Keywords}

Adult, Undernutrition, Inpatients 


\section{Background}

The high global burden of malnutrition in hospitalized patients has been widely documented. Undernutrition, is a common and costly problem among patients in hospitals [1]-[6]. In developing countries, adult undernutrition is common among hospitalized adult's patients and is a burden on patients and health care facilities, but not documented. Consequences of this malnutrition include increased morbidity, mortality, complications, healthcare costs and the length of hospital stay [7] [8] [9]. The prevention and treatment of hospital undernutrition offers an opportunity to optimize the overall quality of care, reduce costs and improve outcomes. Unfortunately, undernutrition continues to be unrecognized and untreated in many hospitalized adults patients. Inadequate detection and intervention of undernutrition can lead to the worsening of nutritional status during hospitalization [10].

Undernutrition in adult's hospitalized patients is the result of a number of factors and may be associated with the disease and/or its treatment [11]. Inadequate dietary intake is one major cause and there are several clinical situations that can cause loss of appetite or impaired food intake [12].

Despite numerous advances in medicine and clinical care, at hospital, the simple correction of an adult's nutritional status appears to be overlooked and not considered as a sufficient medical priority.

The objective of this study was to identify the magnitude of adult undernutrition and its associated factors in hospitalized patients.

\section{Methods}

\subsection{Study Design, Setting and Participants}

This was a cross-sectional observational study, carried out in the university hospital in Bobo-Dioulasso (Burkina Faso). Data collection was conducted from August to September 2016. Adult's patients ( $\geq 18 \mathrm{y}$ old) hospitalized in medicine and surgery department were included.

The non-inclusion criteria were patients unable to communicate or to be assessed by anthropometric parameters.

Patients were informed about the study objectives and their free consent to participate were obtained.

\subsection{Sample Size}

The sample size estimation used the procedures for determining sample for cross-sectional observational study.

The following basic equation has been used to calculate the required sample size

$$
n=Z_{\alpha}^{2} P Q / \delta^{2}
$$

$n=$ required minimum sample size

$Z_{\alpha}=1.96$, the $Z$-score corresponding to the desired degree of confidence 
(=95\% means $\alpha=5 \%)$

$P=$ the estimated level of hospital adults undernutrition $(P=30 \%), Q=100-$ $P(Q=70 \%)$

$\delta=$ the precision of the estimation ( $\delta=6 \%$ in this procedure)

Sample size (including non-responses rate) was 244 hospitalized adult's patients.

\subsection{Sampling}

In each medical unity, patients were included in the study consecutively to their admission.

\subsection{Variables and Data Collection}

A structured and pretested questionnaire was used consisting of data related to: patient identification (personal and demographic data: age, sex, education, profession, residence, marital status), medical information (data of admission, reason for hospital admission, duration of the disease evolution, clinical signs and diagnosis); nutritional data (appetite assessment); data on food consumption (recent dietary changes and description of present diet); observation of clinical signs of nutritional deficiencies (observation of hair, skin and presence of nutritional edema); recent and unintentional weight loss; risk behavior (alcohol consumption, cigarette smoke) and evaluation of anthropometric data (weight, height, Mid-Upper Arm Circumference (MUAC)).

A regular diet was investigated in the last week before hospital admission.

To avoid biases in data collection and interpretation, interviews and anthropometric measurements were carried by a single examiner, a trained health worker who speaks local languages.

Weight was measured in kilograms $(\mathrm{kg})$ with a portable scale, height was measured in meter $(\mathrm{m})$ with stadiometer and. Mid-Upper Arm Circumference $(M U A C)$ was measured in centimeter $(\mathrm{cm})$ with adult MUAC inelastic measuring tape.

To calculate the body mass index (BMI), weight $(\mathrm{kg})$ was divided by height (m) squared.

The criterion adopted for the diagnosis of undernutrition was the presence of at least one of the following anthropometric parameters: $\mathrm{BMI}<18.5 \mathrm{~kg} / \mathrm{m}^{2}$ or MUAC $<22 \mathrm{~cm}$.

\subsection{Data Analysis}

The data were entered, cleaned and checked for missing values and outliers, and analyzed using IBM SPSS statistics for windows, version 20.0. Undernutrition was considered a binary variable (presence or absence). Simple descriptive analyses were used to describe undernutrition and characteristics of the study population. The rate of undernutrtion was reported using frequency distribution. The associations between undernutrtion and independent variables were tested 
using the Chi-square test. Unadjusted crude Odds ratios (COR) with 95\% confidence interval (95\% CI) was used to investigate the factors independently associated with undernutrtion. All of the results were considered statistically significant at $\mathrm{p}$-value $<0.05$.

\subsection{Ethical Considerations}

Authorization was obtained from hospital. At the time of data collection, a verbal and written consent was taken from the participants to confirm whether they are willing to participate or to obtain oral consent. Information was collected after securing consent from study participants. Data obtained from each study participant were kept confidential.

\section{Results}

\subsection{Socio-Demographic Characteristics of the Participants}

The population consisted of 244 patients, $36.5 \%$ female and $63.5 \% \%$ male. The mean age was 48.2 years $(\mathrm{SD}=17.2$ years). A third $(33.2 \%)$ of the patients was farmers. The high proportion (81.5\%) of patient was married. More than two third $(69.7 \%)$ of patients were not schooled (Table 1).

\subsection{Magnitude of Undernutrition}

Undernutrition occurred in $32.4 \%$ of the sample. The majority of the undernourished individuals were under 70 years old $(88.6 \%)$.

\subsection{Associated Factors of Undernutrition}

At the univariate analysis, the variables associated with undernutrition were: recent and involuntary weight loss $(\mathrm{COR}=2.58,95 \% \mathrm{CI}=1.45-4.59, \mathrm{p}<0.001)$; disease chronic evolution $(\mathrm{COR}=2.29,95 \% \mathrm{CI}=1.23-4.23, \mathrm{p}=0.008)$ and females $(\mathrm{COR}=1.76,95 \% \mathrm{CI}=1.02-6.06, \mathrm{p}=0.04)$.

Concerning clinical signs, the percentage of undernourished patients was higher between patients with vomiting (40\%), diarrhea (36.7\%) and with anorexia $(32.4 \%)$. But vomiting, diarrhea and anorexia during hospitalization were not statistically associated with undernutrtion.

Concerning food consumption, the dietary diversity was not associated with undernurtition (Table 2).

Table 1. Characteristics of the patients.

\begin{tabular}{cccc}
\hline & $\mathrm{n}$ & $\%$ & Mean (SD) \\
\hline Mean age (y) & $\mathbf{2 4 4}$ & & $\mathbf{4 8 . 2}(\mathbf{1 7 . 2 )}$ \\
Marital status & & & \\
In a relationship & 199 & 81.5 & \\
$\quad$ Single & 45 & 18.5 & \\
Formal school education of mothers & & & \\
Yes & 74 & 30.3 & \\
No & 170 & 69.7 & \\
\hline
\end{tabular}


Table 2. Univariate analysis showing association of factors with undernutrition among hospitalized adults, Bobo-Dioulasso 2016.

\begin{tabular}{|c|c|c|c|c|}
\hline & $\mathrm{n}$ & $\begin{array}{c}\% \text { of } \\
\text { Undernourished } \\
\text { patients }\end{array}$ & COR [IC 95\%] & p-value \\
\hline \multicolumn{5}{|c|}{ Recent and involuntary weight loss } \\
\hline Yes & 136 & $41.2 \%$ & $2.58(1.45-4.59)$ & \multirow{2}{*}{$0.001^{* * *}$} \\
\hline No & 108 & $21.3 \%$ & 1.0 & \\
\hline \multicolumn{5}{|l|}{ Age (y) } \\
\hline$<70$ & 207 & 33.8 & $1.59(0.71-3.55)$ & \multirow{2}{*}{0.25} \\
\hline$>70$ & 37 & 24.3 & 1.0 & \\
\hline \multicolumn{5}{|l|}{ Sex } \\
\hline Female & 89 & 40.4 & $1.76(1.02-6.06)$ & \multirow{2}{*}{$0.041^{*}$} \\
\hline Male & 155 & 27.7 & 1.0 & \\
\hline \multicolumn{5}{|l|}{ Disease evolution } \\
\hline Chronic & 94 & 40.2 & $2.29(1.23-4.23)$ & \multirow{2}{*}{$0.008^{* *}$} \\
\hline Acute & 105 & 22.9 & 1.0 & \\
\hline \multicolumn{5}{|l|}{ Diarrhea } \\
\hline Yes & 30 & 36.7 & $1.23(0.55-2.73)$ & \multirow{2}{*}{0.6} \\
\hline No & 213 & 31.9 & 1.0 & \\
\hline \multicolumn{5}{|l|}{ Vomiting } \\
\hline Yes & 45 & 40 & $1.49(0.76-2.92)$ & \multirow{2}{*}{0.235} \\
\hline No & 198 & 30.8 & 1.0 & \\
\hline \multicolumn{5}{|l|}{ Alcohol consumption } \\
\hline Yes & 46 & 43.5 & $1.81(0.93-3.49)$ & \multirow{2}{*}{0.074} \\
\hline No & 198 & 29.8 & 1.0 & \\
\hline \multicolumn{5}{|l|}{ Cigarette smoke } \\
\hline Yes & 28 & 46.4 & $1.94(0.87-4.31)$ & \multirow{2}{*}{0.1} \\
\hline No & 204 & 30.9 & 1.0 & \\
\hline \multicolumn{5}{|l|}{ Anorexia } \\
\hline Yes & 102 & 32.4 & $1.04(0.60-1.81)$ & \multirow{2}{*}{0.87} \\
\hline No & 137 & 31.4 & 1.0 & \\
\hline \multicolumn{5}{|l|}{ Dietary diversity } \\
\hline No & 145 & 34.3 & $1.15(0.66-1.99)$ & \multirow{2}{*}{0.58} \\
\hline Yes & 99 & 31 & 1.0 & \\
\hline
\end{tabular}

\section{Discussion}

This study is a cross-sectional observational study with some limitation. It has been showed that undernutrition magnitude in hospital vary by method of assessment. For the purposes of this study, the criterion adopted for the diagnosis 
of undernutrition was the presence of at least one of the following anthropometric parameters: $\mathrm{BMI}<18.5 \mathrm{~kg} / \mathrm{m}^{2}$ or MUAC $<22 \mathrm{~cm}$. Throughout the literature, a variety of tools and definitions have been used for undernutrition evaluation. Regarding the data on consumption, in this study, a regular diet was investigated in the last week before hospital admission, but the total energy value has not been evaluated.

Adult undernutrition was common among hospitalized patients in this study, $36.5 \%$ of the sample were undernourished. Differences of observed frequency of adult undernutrition between studies can be due to the difference of definition, tools used for measurement and adult undernutrition diagnosis criteria. But the high magnitude of hospital adult undernutrition was similar to other studies carried out in the world [4] [5] [6]. If left untreated, approximately two thirds of those patients will experience a further decline in their nutrition status during hospitalization [13]. The treatment of undernutrition offers an opportunity to optimize the overall quality of patient care, improve clinical outcomes, and reduce costs. The adequate treatment of undernutrition first requires malnourished patients to be identified on admission and during hospitalization. The negative consequences of undernutrition have been widely reported in the literature [1] [13]-[22]. Undernutrition may result, during hospitalization, in increased morbidity (such as higher infection rates and complications); increased risk of negative health outcomes and mortality. At a psychological level, undernutrition is associated with fatigue and apathy, exacerbates anorexia and increases convalescence time [23]. Undernutrition also affects the length of hospital stays. Researchers funded from study of hospitalized patients that the median length of stay for malnourished patients was significantly longer than the median length of stay for patients who were not malnourished [8] [9] [15] [24] [25]. Undernutrition may also result in increased healthcare expenditures [7].

In our study, weight loss was the main observed variable and the strongest predictor of adult undernutrition $(\mathrm{COR}=2.58,95 \% \mathrm{CI}=1.45-4.59, \mathrm{p}<0.001)$. Weight loss was the main associated factor identified by some authors [26]. The process of weight loss is considered a process of undernutrition. But, weight loss is not easy to quantify.

In this study, chronic disease evolution increased the risk of undernutrition. This can due to the decrease of appetite during chronic evolution of a disease. Decreased appetite will reduce food intake.

Even if in this study, all variables associated with the digestive tract (vomiting, diarrhea) were not associated to undernutrition, commonly gastrointestinal tract symptoms are usually a result of disease or treatment consequence and may have an impact on nutritional status of the patient, as they affect food intake.

In this study, the dietary diversity was not associated with undernurtition. But maybe, the food diversity index is not appropriate for food intake assessment. It is known that inadequate food intake was a factor associated with undernutrition and that the average energy consumption was lower among undernourished patients than non-malnourished [27]. 
In our study, the female sex was a factor associated with malnutrition $(\mathrm{COR}=$ $1.76,95 \% \mathrm{CI}=1.02-6.06, \mathrm{p}=0.04)$. In some studies the male sex was a factor associated with malnutrition [28]. To discuss the difference of findings, social factors in hospitalized patients are important. In a study [29], authors founded that that weight loss during hospitalization was higher in women than in men. In some social context, women attend healthcare services later than men and are much less attentive to changes in weight and food consumption as they are economically dependent and have a great workload. Thus, the hypothesis is that, when women are hospitalized, they may have more chances of being undernourished than men in our context.

\section{Conclusion}

Adult undernutrition is common in hospitalized patients. After the analysis, recent weight loss, disease chronic evolution and female sex were associated with undernutrition. Adult undernutrition treatment in hospitalized patients is a major challenge as that malnutrition is associated with many adverse outcomes, including an increased risk of morbidity, longer length of hospital stay, higher treatment costs, and increased mortality. A proper early diagnosis and therapy need to be considered as medical priority of the entire healthcare team that treats adult's inpatients.

\section{Acknowledgements}

The authors are grateful to the patient, their family and to the healthcare teams.

\section{Author Contributions}

All authors contributed to study design, literature review, data collection, data analysis and interpretation, and writing. All authors revised and agreed on the views expressed in the manuscript.

\section{Conflicts of Interest}

The authors declare no conflict of interest.

\section{References}

[1] Bistran, B.R., Blackburn, G.L., Vitale, J., Cochran, D. and Naylor, J. (1976) Prevalence of Malnutrition in General Patients. JAMA, 233, 1567-1570. https://doi.org/10.1001/jama.1976.03260410023017

[2] Kamath, S.K., Lawler, M., Smith, A.E. and Olson, R. (1986) Hospital Malnutrition: A 33-Hospital Screening Study. Journal of the American Dietetic Association, 86, 203-206.

[3] Coats, K.G., Morgan, S.L., Bartolucci, A.A. and Weinsier, R.L. (1993) Hospital Associated Malnutrition: A Reevaluation Twelve Years Later. Journal of the American Dietetic Association, 93, 27-33. https://doi.org/10.1016/0002-8223(93)92126-I

[4] Waitzberg, D.L., Caiaffa, W.T. and Correia, M.I.T.D. (2001) Hospital Malnutrition: The Brazilian National Survey (IBRANUTRI): A Study of 4000 Patients. Nutrition, 
17, 573-580. https://doi.org/10.1016/S0899-9007(01)00573-1

[5] Correia, M.I.T.D. and Campos, A.C.L. (2003) Prevalence of Hospital Malnutrition in Latin America: The Multicenter ELAN Study. Nutrition, 19, 823-825. https://doi.org/10.1016/S0899-9007(03)00168-0

[6] O’Flynn, Peake, H., Hickson, M., Foster, D. and Frost, G. (2005) The Prevalence of Malnutrition in Hospitals Can Be Reduced. Clinical Nutrition, 24, 1078-1088. https://doi.org/10.1016/j.clnu.2005.08.012

[7] Sullivan, D.H., Bopp, M.M. and Roberson, P.K. (2002) Protein-Energy Undernutrition and Life-Threatening Complications among the Hospitalized Elderly. Journal of General Internal Medicine, 17, 923-932. https://doi.org/10.1046/j.1525-1497.2002.10930.x

[8] Chima, C.S., Barco, K., Dewitt, M.L., Maeda, M., Teran, J.C. and Mullen, K.D. (1997) Relationship of Nutritional Status to Length of Stay, Hospital Costs, and Discharge Status of Patients Hospitalized in the Medicine Service. Journal of the American Dietetic Association, 97, 975-978.

https://doi.org/10.1016/S0002-8223(97)00235-6

[9] Pichard, C., Kyle, U.G., Morabia, A., et al. (2004) Lean Body Mass Depletion at Hospital Admission Is Associated with an Increased Length of Stay. American Journal of Clinical Nutrition, 79, 613-618. https://doi.org/10.1093/ajcn/79.4.613

[10] Kyle, U.G., Schneider, S.M., Pirlich, M., Lochs, H., Hebuterne, X.T. and Pichard, C. (2005) Does Nutritional Risk, as Assessed by Nutritional Risk Index, Increase during Hospital Stay? A Multinational Population-Based Study. Clinical Nutrition, 24, 516-524. https://doi.org/10.1016/j.clnu.2005.04.003

[11] Raslan, M., Gonzalez, M.C., Dias, M.C.G., Nascimento, M., Castro, M., Marques, P., et al. (2010) Comparison of Nutritional Risk Screening Tools for Predicting Clinical Outcomes in Hospitalized Patients. Nutrition, 26, 721-726. https://doi.org/10.1016/j.nut.2009.07.010

[12] Kondrup, J., Johansen, N., Plum, L.M., Bak, L., Hojlund Larsen, I., Martinsen, A., et al. (2002) Incidence of Nutritional Risk and Causes of Inadequate Nutritional Care in Hospitals. Clinical Nutrition, 21, 461-468. https://doi.org/10.1054/clnu.2002.0585

[13] Somanchi, M., Tao, X. and Mullin, G.E. (2011) The Facilitated Early Enteral and Dietary Management Effectiveness Trial in hospitalized Patients with Malnutrition. Journal of Parenteral and Enteral Nutrition, 35, 209-216. https://doi.org/10.1177/0148607110392234

[14] Bistrian, B.R., Blackburn, G.L., Hallowell, E. and Heddle, R. (1974) Protein Status of General Surgical Patients. JAMA, 230, 858-860. https://doi.org/10.1001/jama.1974.03240060028025

[15] Braunschweig, C., Gomez, S. and Sheean, P.M. (2000) Impact of Declines in Nutritional Status on Outcomes in Adult Patients Hospitalized for More Than 7 Days. Journal of the American Dietetic Association, 100, 1316-1322. https://doi.org/10.1016/S0002-8223(00)00373-4

[16] Callahan, C.M. and Wolinsky, F.D. (1996) Hospitalization for Pneumonia among Older Adults. The Journals of Gerontology, 51, M276-M282. https://doi.org/10.1093/gerona/51A.6.M276

[17] Sullivan, D.H. (1992) Risk Factors for Early Hospital Readmission in a Select Population of Geriatric Rehabilitation Patients: The Significance of Nutritional Status. Journal of the American Geriatrics Society, 40, 792-798. https://doi.org/10.1111/j.1532-5415.1992.tb01851.x

[18] Schneider, S.M., Hebuterne, et al. (2004) Malnutrition Is an Independent Factor 
Associated with Nosocomial Infections. British Journal of Nutrition, 92, 105-111. https://doi.org/10.1079/BJN20041152

[19] Kassin, M.T., Owen, R.M., Perez, S.D., et al. (2012) Risk Factors for 30-Day Hospital Readmission among General Surgery Patients. Journal of the American College of Surgeons, 215, 322-330. https://doi.org/10.1016/j.jamcollsurg.2012.05.024

[20] Krumholz, H.M. (2013) Post-Hospital Syndrome-An Acquired, Transient Condition of Generalized Risk. The New England Journal of Medicine, 368, 100-102. https://doi.org/10.1056/NEJMp1212324

[21] Kirkland, K.B., Briggs, J.P., Trivette, S.L., Wilkinson, W.E. and Sexton, D.J. (1999) The Impact of Surgical-Site Infections in the 1990s: Attributable Mortality, Excess Length of Hospitalization, and Extra Costs. Infection Control \& Hospital Epidemiology, 20, 725-730. https://doi.org/10.1086/501572

[22] Elixhauser, A. and Steiner, C. (2013) Readmissions to US Hospitals by Diagnosis, 2010. Healthcare Cost and Utilization Project Statistical Brief \#153. http://www.hcup-us.ahrq.gov/reports/statbriefs/sb153.pdf

[23] Kubrack, C. and Jensen, L. (2007) Malnutrition in Acute Care Patients. International Journal of Nursing Studies, 44, 1036-1054. https://doi.org/10.1016/j.ijnurstu.2006.07.015

[24] Thomas, D.R., Zdrowski, C.D., Wilson, M.M., et al. (2002) Malnutrition in Subacute Care. The American Journal of Clinical Nutrition, 75, 308-313. https://doi.org/10.1093/ajcn/75.2.308

[25] Kruizenga, H.M., Tulder, M.W.V., Seidell, J.C., Thijs, A., Ader, H.J. and Van Bokhurst-de van der Schueren, M.A.E. (2005) Effectiveness and Cost-Effectiveness of Early Screening and Treatment of Malnourished Patients. The American Journal of Clinical Nutrition, 82, 1082-1089. https://doi.org/10.1093/ajcn/82.5.1082

[26] Kruizenga, H.M., Seidell, J.C., Vet, H.C.W., Wierdsma, N.J. and Van Bokhorstde van der Schueren, M.A.E. (2005) Development and Validation of a Hospital Screening Tool for Malnutrition: The Short Nutritional Assessment Questionnaire. Clinical Nutrition, 24, 75-82. https://doi.org/10.1016/j.clnu.2004.07.015

[27] De Cássia De Aquino, R. and Tucunduva Philippi, S. (2011) Identification of Malnutrition Risk Factors in Hospitalized Patients. Revista da Associação Médica Brasileira, 57, 623-629. https://doi.org/10.1016/S0104-4230(11)70127-0

[28] Pirlich, M., Schütz, T., Kemps, M., Luhman, N., Minko, N., Lübke, J.H., et al. (2005) Social Risk Factors for Hospital Malnutrition. Nutrition, 21, 295-300. https://doi.org/10.1016/j.nut.2004.06.023

[29] Splett, P.L., Roth-Yousey, L.L. and Vogelzang, J.L. (2003) Medical Nutrition Therapy for the Prevention and Treatment of Unintentional Weight Loss in Residential Healthcare Facilities. Journal of the American Dietetic Association, 103, 352-362. https://doi.org/10.1053/jada.2003.50050 